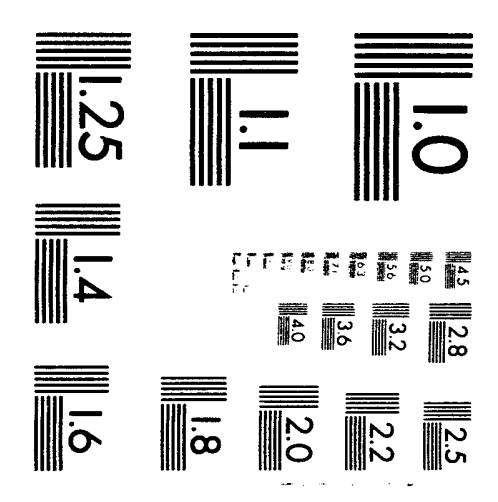



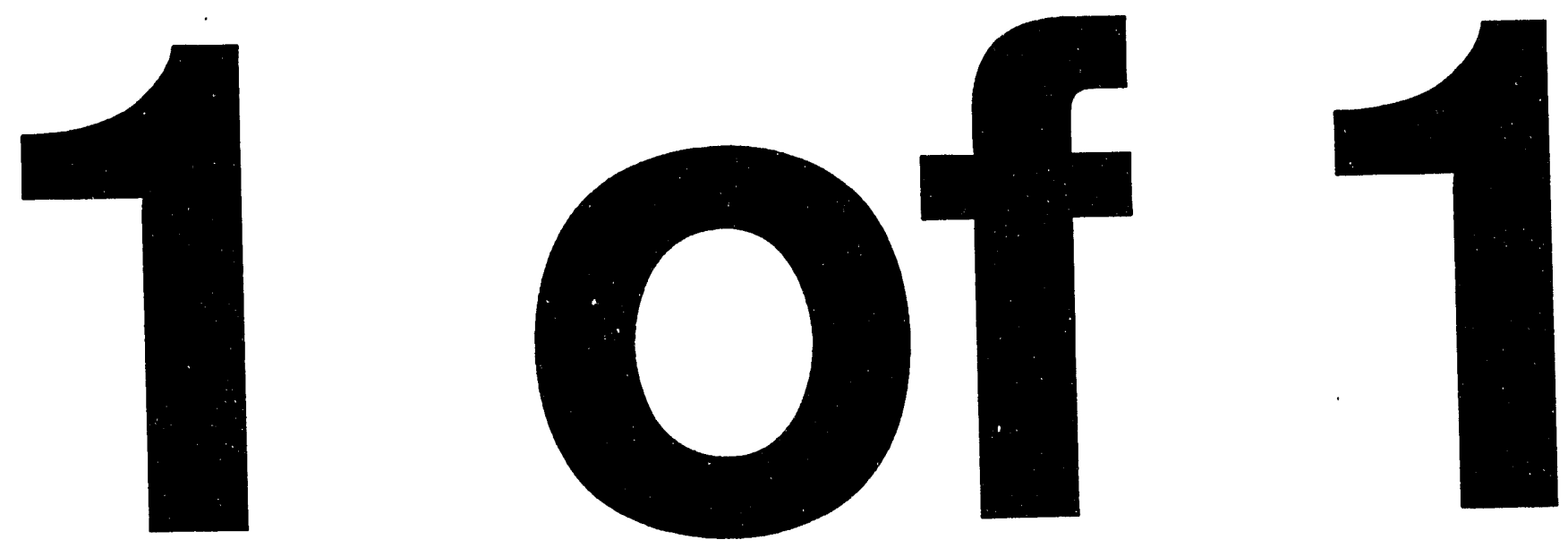


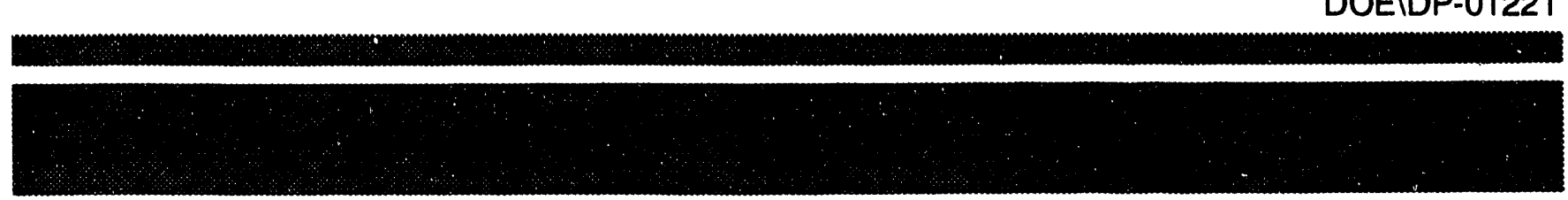

\section{Overview \\ of the \\ Defense Programs \\ Research and Technology \\ Development Program \\ for \\ Fiscal Year 1993}

\section{Appendix II}

Research Laboratories

\section{and Facilities}

September 30, 1993

\section{US Department of Energy}

Assistant Secretary for Defense Programs

Deputy Assistant Secretary for Military Application

Office of Research and Advanced Technology

Research and Technology Development Division 
This document was prepared by representatives of

Sandia, Los Alamos, and Lawrence Livermore National Laboratories at the request of:

\author{
Gregory J. D'Alessio, Director \\ Research and Technology Development Division, DP-242 \\ Office of Research and Advanced Technology \\ Defense Programs \\ U.S. Department of Energy \\ Washington, DC
}

For further information, contact:

\author{
James Asay \\ Department 5602, MS 0458 \\ Sandia National Laboratories \\ P.O. Box 5800 \\ A].buquerque, NM 87185 \\ LARRY Madsen \\ MS F629 \\ Los Alamos National Laboratory \\ Los Alamos, NM 87545

\section{JOSEPH KeLLeR} \\ MS L2O \\ Lawrence Iivermore National Laboratory \\ P.0. Box 808 \\ Livermore, CA 94550
}


TABLE OF CONTENTS

Summary ....................... 3

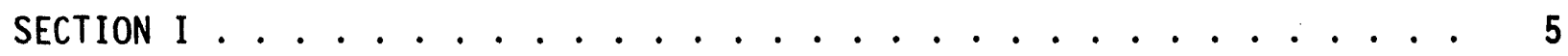

MAJOR RESEARCH FACILITIES AND LABORATORIES ......... 6

MAJOR RESEARCH FACILITIES BY PROGRAM ELEMENT . . . . . . . . 11

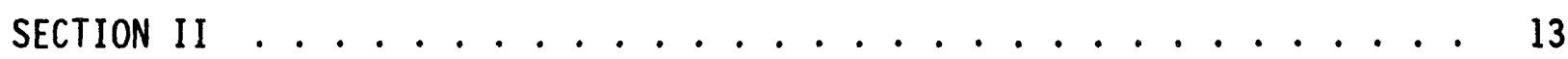

LANL INPUT FOR FACILITIES LISTING . . . . . . . . . . . . 14

LLNL INPUT FO! FACILITIES LISTING . . . . . . . . . . . . . . 19

SNL INPUT FOR FACILITIES LISTING . . . . . . . . . . . 26 


\section{Program Element Plan RESEARCH FACILITY SUMMARY}

The pages that follow contain summaries of the research facilities that support the Defense Programs Research and Technology Development Program, as shown in the R\&TD Program Element Plan for FY 1993. (See DOE/UF-0122T.) The nine program elements are aggregated into three program clusters as follows:

Acvanced Materials Sciences and Teishologies

Chemistry and Materials

- Explosives

- Special Nuclear Materials (SNM)

- Tritium

Design Sciences and Advanced Computation

- Physics

- Conceptual Design and Assessment

- Computation and Modeling

Advanced Manufacturing Technologies and Capabilities

- System Engineering Science and Technology

- Electronics, Photonics, Sensors, and Mechanical Components

The Research and Technology Development Program provides the primary resources for the operation, maintenance, and construction of Defense Programs Weapons Research and Development (R\&D) (science and technology base activities) facilities, and laboratories at Los Alamos National Laboratory (LANL), Lawrence Livermore National Laboratory (LLNL), and Sandia National Laboratories (SNL). The only exceptions are those facilities operated by the Inertial Confinement Fusion (ICF) Program (NOVA at LLNL; PBFA II at SNL; and the Target Fabrication Lab at (ANL); those weapons test ranges and weapons test facilities operated by SNL from the Testing budget; and weapon engineering/stockpile maintenance activities in weapon engineering facilities funded under the Weapon Development and Certification budget.

The Research and Technology Program supports annual research budgets in existing laboratories (advanced manufacturing science and technology, advanced materials science and technology, electronics technology development, components technology, robotics, etc.) and on major research facilities (advanced computation, weapons physics facilities). In FY 93 over 200 weapons RD\&T laboratories and facilities were identified at LANL, LLNL, and SNL. of these approximately 20 can be generally categorized as "major" DP research and technology development facilities as shown below. 
Section I gives a brief summary of 23 major DP research and technology facilities and shows how these major facilities are organized by program elements. Section II gives a more detailed breakdown of the over 200 research and technology facilities being used at the Laboratories to support the Defense Programs mission. This database was based on the best available data provided to Headquarters DOE by the laboratories as of the end of fiscal year 1993. 


\section{SECTION I}

MAJOR RESEARCH FACILITIES AND LABORATORIES 


\section{MAJOR RESEARCH FACILITIES AND LABORATORIES}

\begin{tabular}{|c|c|c|c|c|}
\hline $\begin{array}{c}\text { Major Facilities/ } \\
\text { Laboratories }\end{array}$ & LANL & LLNL & SNL & TOTAL \\
\cline { 2 - 5 } & 10 & 6 & 7 & 23 \\
\hline
\end{tabular}

\section{LANL:}

Central Computing Facility - The most powerful of LANL's production computers are four Cray Y-MPs made by Cray Research, Inc. The CM-5 from Thinking Machines represents the state of the art in massively parallel computing. Two other massively parallel computers (Thinking Machines' $\mathrm{CM}-2$ ) each having $64 \mathrm{~K}$ processors and 8 Gbytes of memory, have the potential to become production-capable computers.

At LANL, an extensive data communications network connects all large computers to an integrated computing network. The network supports over 200 computer systems, including both the large supercomputers in the central site and the remote multi-user systems called distributed processors. The network provides computing services to over 8,000 computer users across the country and allows rapid access to the major computers and other systems while minimizing duplication of resources.

Detonation Systems Lab - The Detonation Systems Laboratory is a 13,207 square foot facility in TA-22 to support design and development of detonation systems for nuclear weapons. It is also used for the design and development of low-energy electroexplosive devices for various weapons applications. Facilities are available for fabrication of detonators, cables, and firing systems used in tests. Also included is support of activities leading to engineering design definitions and quality requirements for DOE contractor production of War Reserve Components.

Dual Axis Radiographic Hydrotest Facility (DARHT) - DARHT is being developed to replace the over 30 year old PHERMEX facility at LANL. It improves on the LLNL FXR by incorporating dual axis $x$-ray radiography of detonating high explosives to provide stereoscopic images of detonating high explosive. The DARHT diagnostic area will be large enough to incorporate LLNL, as well as LANL diagnostics. The maximum explosive weight placed at the 2-axis intersection point for DARHT has been set at $70 \mathrm{~kg}$. The spot size goal has be set at 1.2 millimeter-diameter 4 rms timeaveraged over 60 nanoseconds.

Los Alamos Critical Experiment Facility (LACEF) - LACEF consists of three remote assembly buildings that house ten general-purpose critical 
assembly machines. These include assemblies such as: Godiva IV, Jezebel, Flat-top, Skua, solution critical, Big Ten, Anaconda, and Viper. For example, a natural uranium reflected system with cores of either plutonium or uranium is used in safety classes so that participants can actually operate a "reactor". Some of the projects conducted here have involved making a neutronic mockup of a New Production Reactor, performing basic measurements on the characteristics of nuclear material, making basic cross-section measurements in an intermediate energy spectrum, and simulating accidents, etc.

LACEF is the last general-purpose nuclear experimental facility of its type in the U.S. Plans are being prepared to develop a center for radiation accident evaluation and dosimetry using the multitude of sources readily available at this site.

Los Al amos Neutron Scattering Center (LANSCE) - The Manuel Lujan, Jr. Neutron Scattering Center (LANSCE) takes proton pulses from the LAMPF/Proton Storage Ring facility to produce intense bursts of spallation neutrons from a tungsten target. Recent completion of an experimental hall addition has greatly increased space for new beam lines and instruments. A support building provides the necessary space for user and staff laboratories and offices. Users from many countries conduct neutron scattering experiments here in solid-state physics, chemistry, crystallography, biophysics, materials science, and nuclear physics.

Pegasus - The Pegasus II 4.3 Megajoule capacitor bank is used to generate pulse power for a variety of weapons physics experiments.
Experiments on Pegasus have demonstrated the symmetric implosion of a solid cylindrical aluminum shell for a variety of high pressure implosion hydrodynamics applications. Pegasus can deliver $12 \mathrm{MA}$ in 6 microseconds. The peak dynamic implosion temperature is about 100 electron volts.

Plutonium Facility (TA-55; CMR B1dg.) - The 169,121 square foot Plutonium Research and Processing Facilities at Los Alamos were built about 1974. Special nuclear materials R\&D, and highly specialized analytical chemistry and metallurgy activities are conducted in the CMR Building, which was completed about 35 years ago. At one time 550 FTEs were involved in plutonium research and processing.

Pulsed High-Enerqy Radiographic Machine Emitting X-Rays (PHERMEX) PHERMEX was the country's first facility to perform weapons system hydrodynamic testing. It contains a large radio-frequency linear accelerator that produces a beam of relativistic electrons with energies of $30 \mathrm{MeV}$. The beam is directed at a tungsten target where the energy of the electrons is converted into bremsstrahlung radiation, most of which is in the $x$-ray range. This is used to provide flash radiography of high explosive systems during detonation.

Tritium Facility - The Weapons Engineering Tritium Facility (WETF) is a 6,300 square foot facility built in 1984 in TA-16 to support boost systems development and provide tritium packaged at high pressures for other Laboratory users. It is highly automated for high pressure tritium and the safety-environmental control systems are also partially automated. The facility was approved by the Energy Secretary for tritium 
operations in April 1991.

Weapons Neutron Research (WNR) Facility - The WNR is a pulsed spallation neutron source used for basic and applied research. A portion of the LAMPF $800-$ Mev proton beam is used either to bombard a heavy-metal target and produce an intense white-neutron source or to irradiate samples in a separate external beam area. By varying the proton pulse structure, experimenters using the WNR can perform neutron time-of-flight studies over an energy range from 100 to $800 \mathrm{MeV}$. Nuclear studies requiring neutrons with energies below $100 \mathrm{keV}$ are conducted nearby at LANSCE.

\section{LLNL:}

Computation Center - The Livermore Computer Center's primary responsibility is to provide a Secure Computing Facility (SCF) to support classified computing at LLNL. The LCC al so supports an unclassified network (Open LabNet) and some its facilities to support unclassified distributed computing at the laboratory.

The centralized computing resources of the SCF are connected by a Hyperchannel Network. Attached resources, such as supercomputers, a hierarchical data-management system, and output processing facilities, are continually enhanced to provide a unified, centralized, state-of-theart computing facility. A starshaped set of 10cal-area Ethernets attached to the Hyperchannel Network connect several thousand remote workstations to the central facility in a dynamically reconfigurable manner.

The computer system is being upgraded to reflect DOD-standard Transmission Control Protocol/Internet Protocol
(TCP/IP) network protocols and massively parallel processing (MPP). LLNL has already installed a BBN TC2000 system as the first MPP and is determining requirements for future systems.

High Explosive Radiographic Flash $X$ Ray (FXR) Facility - The FXR is a Tinear-induction accelerator housed in Bunker 801 at Site 300 . It can generate $20-\mathrm{MeV}$ electrons at $4000 \mathrm{~A}$ to support the nuclear design program objectives. The $x$-rays produced when the electron beam strikes a tungsten target give a dose of about $500 \mathrm{R}$ at 1 meter with a single-pulse length of about 70 nanoseconds. The spot size is roughly 2 to 3 millimeters.

High Explosive Application Facility (HEAF) - Synthesis, formulation, and performance testing of a new explosive compound can all be carried out within LLNL's HEAF complex. HEAF provides 108,000 gross square feet, including 50,000 net square feet of experimental areas and 13,000 square feet of office space for approximately 60 scientists and 400 support personnel. Combining all of these operations into one facility allows enhanced interaction among the LLNL high-explosives scientists (most of whom have their offices in HEAF) as well as the ability to move oneof-a-kind diagnostics from one experiment to another within the facility. Further, HEAF permits fast turnaround of repetitive experiments, operations that are independent of the weather, and close supervision of the experiments by the scientists who designed them. The HEAF is composed of a synthesis and formulation area, a small-scale testing area, an inert fabrication and testing area, a shot assembly area, an HE experimentation area, and a theory and modeling area.

NOVA - The NOVA laser supports the inertial confinement fusion program. 
Experiments include the following target physics issues in radiatively driven targets: laser-plasma interaction physics, the efficiency of laser light conversion to x-rays, hohl raum characterization and design, hydrodynamic stability, and implosion physics. Experiments aimed at a greater understanding of nuclear weapon physics have been conducted with NOVA for several years. The laser can operate routinely with $40 \mathrm{~kJ}$ at 0.35 micrometers, a beam-to-beam power balance of 5 to 10 percent, and a pointing precision of each beam within a 30 micrometer accuracy.

Plutonium Research Bldg - The research and development capability on plutonium, its alloys, and compounds is provided by the Plutonium Facility (B332) is a critical component of the Defense Systems Program at LLNL. The Plutonium Facility contains a fully equipped device component fabrication facility that provides casting, machining, welding, inspection, assembly, and radiography services, as well as fully equipped analytical chemistry and metallographic capabilities. Existing unique capabilities include, for example, pyrochemical processing, precision machining, and laser welding.

Tritium Building - This building was built in 1959 and is approximately 29,000 square feet. It was designed to develop device components for nuclear tests at the Nevada Test Site. It supported basic research in the physical properties of liquid and solid tritium-containing hydrogen isotopes, the filling of glass microsphere targets for the inertial confinement fusion program, and various research and development programs in support of the national Magnetic Fusion effort and Weapons Programs. The LLNL tritium building is currently being readied for transition to other uses.

\section{SNL:}

Component Development Laboratory (explosives) - The primary function of the facility is research and development associated with explosive components and propellant devices. A secondary function is specialized testing to determine the response of a wide range of energetic materials to abnormal environments. This facility will be replaced by the Explosives Components Facility (ECF) when it is completed.

Computation Center - Services provided on the Albuquerque Central Computer Network include a Cray $X$ MP/416 and a Cray 1S. A file server, the Integrated File system is connected to the network buses. Gateway computers provide access to the network buses from 80 distributed VAX computers.

The major scientific computing systems within the Livermore Central Computing Facility are the Cray YMP. $8 / 264$ and $X-M P / 24$. Two VAX 8700s, two VAX $8650 \mathrm{~s}$, and three VAX $11 / 780 \mathrm{~s}$ are used to provide low-power, userfriendly, time-sharing computing capacity as well as terminal concentration to the Cray systems. A gateway VAX-11/780 provides communications to Albuquerque via a 56-kilobits per second secure communication line.

Hermes II \& III - The Hermes machines are linear induction accelerators primarily operated for nuclear effects testing. However, it is also the primary test bed for the development of intense gamma ray simulators and is very important to the development of both the Externally Driven Nuclear Assembly (EDNA) and the Laboratory Microfusion 
Facility, both of which address problems previously handled by under ground testing. In the past, reentry vehicles, missile and satellite components, and subsystems have been tested in the radiation environments generated by the PBFA machines.

Microelectronics Development Laboratory - The silicon microelectronics projects that are currently underway in the MDL (BIdg 858) will impact future DP programs in the areas of radiation hardened integrated circuits, ferroelectric nonvolatile memories, smart sensors, advanced packaging, and smart micromechanical devices. The IC technology used for these projects is a modified version of Sandia's radiation hardened technology and the MDL serves as an alternate supplier of radiation hardened circuits for government applications.

This facility will be adequate for government IC development for perhaps a decade, if the equipment is continuousiy updated. The MDL can supply radiation tolerant circuits for only about three more years without significant equipment replacements.

Particle Beam Fusion Accelerator II (PBFA II) - PBFA II is used to generate intense ion beams in support of the inertial confinement fusion program. It has produced a beam of 10 million volts, generated a diode current of 3 million amperes, reached 100 percent purity of the lithium beam and achieved more than 70 percent electrical conversion efficiency. Program scientists hope to eventually produce an ion beam of about 1 million joules, five times the current level.

Robotics Manufacturing Science and Engineering Labc atory (RMSEL) - This 64,000 square foot laboratory is being acquired to provide facilities for the development of robotic technologies required to satisfy future robotics and automation needs at Sandia and within the DOE complex. Future DOE weapons plants will implement extensive robotics and automation technology to meet environmental, safety, and health goals. In addition, DOE environmental restoration and waste management activities will rely on robotics systems to safely perform many of the operations. The building will provide laboratory space for robots, vibration-isolated sensor labs, and computer modeling and system simulation capabilities located within the same laboratory module to facilitate robotics technologies development.

Saturn Facility - The Saturn facility in Tech Area IV is operated for nuclear weapons effects testing and for imploding plasmas for $x$-ray production. It has developed 300-500 kilojoule, soft $x$-rays and has been used to power successful trilaboratory radiation flow experiments in centimeter size hohlraums in the past. It is critical to our threat assessment mission in $x$-ray lasers and to radiation flow studies for both the inertial fusion and weapons physics. 


\begin{tabular}{|c|c|c|c|}
\hline \multicolumn{4}{|c|}{ MAJOR RESEARCH FACILITIES BY PROGRAM ELEMENT } \\
\hline ELEMENT & LANL & LLNL & SNL \\
\hline $\begin{array}{l}\text { Chemistry \& } \\
\text { MATERIALS }\end{array}$ & $\begin{array}{l}\text { LANSCE } \\
\text { CMR BLDG }\end{array}$ & & $\begin{array}{c}\text { MICROELECTRONICS } \\
\text { DEV LAB }\end{array}$ \\
\hline EXPLOSIVES & $\begin{array}{l}\text { DETONATION } \\
\text { SYSTEMS LAB }\end{array}$ & HEAF & $\begin{array}{c}\text { COMPONENT } \\
\text { DEVELOPMENT LAB }\end{array}$ \\
\hline SNM & Plutonium fac & $\begin{array}{l}\text { PLUTONIUM } \\
\text { FACILITY }\end{array}$ & \\
\hline TRITIUM & TRITIUM FACILITY & TRITIUM BUILDING & TRITIUM RES LAB \\
\hline Phrsics & $\begin{array}{l}\text { DARHT } \\
\text { PHERMEX } \\
\text { WNR } \\
\text { LANSCE } \\
\text { PEGASUS }\end{array}$ & $\begin{array}{l}\text { FXR } \\
\text { NOVA }\end{array}$ & $\begin{array}{c}\text { MICROELECTRONICS } \\
\text { DEV LAB } \\
\text { HERMES } \\
\text { PBFA II } \\
\text { SATURN } \\
\end{array}$ \\
\hline $\begin{array}{l}\text { CONCEPTUAL } \\
\text { DESIGN \& } \\
\text { ASSESSMENT }\end{array}$ & & & \\
\hline
\end{tabular}




\begin{tabular}{||c|c|c|c||}
\hline \multicolumn{2}{||c|}{ MAJOR RESEARCH FACILITIES BY PROGRAM ELEMENT } \\
\hline ELEMENT & LANL & LLNL & SNL \\
\hline COMPUTATION & $\begin{array}{c}\text { CENTRAL } \\
\text { COMPUTING } \\
\text { FACILITY }\end{array}$ & $\begin{array}{c}\text { COMPUTATION } \\
\text { CENTER }\end{array}$ & $\begin{array}{c}\text { COMPUTATION } \\
\text { CENTER }\end{array}$ \\
\hline $\begin{array}{l}\text { SYSTEMS } \\
\text { ENGINEERING } \\
\text { SCIENCE \& } \\
\text { TECHNOLOGY }\end{array}$ & & $\begin{array}{c}\text { RMSEL } \\
\text { COMPONENT } \\
\text { DEVELOPMENT LAB } \\
\text { MICROELETRONICS } \\
\text { DEV LAB }\end{array}$ \\
\hline COMPONENTS & & $\begin{array}{c}\text { MICROELECTRONICS } \\
\text { DEV LAB }\end{array}$ \\
\hline
\end{tabular}


SECTION II

RESEARCH FACILITIES BY PROGRAM ELEMENT 


\section{LANL INPUT FOR FACILITIES LISTING}

\section{Weapons Materials Cluster}

\section{A. Chemistry and Materials Element}

1. Metallurgy:

-Metallurgical labs of the Materials Technology Facility (Sigma Site Complex)

- Advanced Materials Sciences Lab, portions

-Target Fabrication Facility (TA-35), portions

2. Ceramics

- Ceramic lab with the Sigma Site Complex

-Advanced Materials Science Lab, portions

-Target Fabrication Facility, portions

3. Organics

-General purpose plastic and adhesives labs within the Sigma Site Complex

-Specialized research capabilities at various locations/sites that directly support specific programs, (e.g. HE plastics and adhesives development at TA-16)

4. Compatibility and Aging

- Variety of environmental chambers and test cells at S-site and other sites

-Basic studies at Sigma complex, Chemistry \& Materials Research (CMR) building and DP site

5. Analysis

- Weapons Diagnostics Instrument Development (WDID) Facility - Contained Experiments Chemistry Facilities

- Rad Chem Counting Facility

-Structure Lab

-Analytical Chemistry Labs of the Chemistry \& Materials Research (CMR) building

-Los Alamos Neutron Scattering Center (LANSCE), portions

6. Materials Supporting Facilities and Capabilities

-Main Machine shop complex

-Co-located branch shops for specialized materials support

B. Explosives (includes HE/IHE R\&D, Advanced explosive research and detonation systems R\&D)

1. Explosives: Basic and Applied R\&D [includes HE, IHE, and new reactive materials/super explosives] -Explosives Technology Facility (TA-40) 
-High Explosives Fabrication and Processing Facility (TA-16)

- HE firing sites and storage bunkers

- Explosives Chemistry R\&D Facilities (TA-9)

-Explosives Analytical Chemistry Facility (TA-16)

- High Pressure Lab (TA-16)

- Thermal Chambers (TA-16)

-Drop Tower and Pad

2. Detonation Systems

- Detonation Systems Lab (TA-22)

-Firing Chambers

\section{Special Nuclear Materials}

1. Metallurgy

-Chemistry \& Materials Research (CMR) metallurgical labs and hot cells

-TA-55 metallurgical labs, Pu foundry

-Oy Foundry-Sigma Complex

2. Processing

- Plutonium Facility (TA-55)

- Nuclear Waste Facility (TA-50)

3. Waste Minimization R\&D

-Plutonium Facility (TA-55)

-Chemistry \& Materials Research (CMR) labs

4. Special Operations

- RadioChemistry Lab

- Nuclear Materials Storage Facility

D. Tritium

- Weapons Tritium Engineering Facility (WETF) (TA-41)

- Tritium Processing Facility (TA-21)

-Tritium Salt Facility (TSF)

-Tritium Systems Test Assembly (TSTA) Facility, portions

\section{Design Sciences and Capabilities Cluster}

A. Physics

1. Hydrodynamics

- Multidiagnostic Hydrotest Facilities (MHF)

- PHERMEX Facility (TA-15)

-DARHT - [replacement for PHERMEX - under construction]

- Confinement Assembly and Testing (CAT) Facility

- Terminal Ballistic Test Facility (TBTF)

- Other specialized firing sites with tailored diagnostics capabilities

2. Neutronics 
- Los Alamos Critical Assemblies at TA-18

[this site includes the Godiva IV, Jezebe], Flat-top, Skua, solution critical, Big Ten, Anaconda, and Viper, which are all specific critical assemblies or zero power reactors that support neutronic and cross-sections measurements]

- Weapons Neutron Research (WNR) facility at LAMPF (TA-53)

-Omeya West Reactor (TA-2, shutdown)

3. Plasma Physics and Radiation Transport

-Pulsed Power Lab

-Explosive Pulsed-Power Firing Complex (TA-39)

- Field Reversed Configuration (FRC) Liner Implosion Facility

- Pegasus II Capacitor Bank

- Trident Laser

- Mercury KrF Laser

4. Atomic and Nuclear Physics

- Weapons Neutron Research (WNR) Facility at LAMPF (TA-53)

- Los Alamos Neutron Scattering Center (LANSCE) at LAMPF (TA-

53)

- Van de Graff and Ion Beam Facility

-Free-Electron Laser

-Ground Test Accelerator (GTA)

- Bright Source Laser II

- Meteor I and II Pulsed Laser Facility

- Omega West Reactor (TA-2, shutdown)

5. Materials Dynamics and EOS

-Plutonium Gas Gun at TA-55

- Two-stage Light Gas Gun

-Single-stage Powder Gun

- Dynamics Materials Characterization Facility

-Firing sites that support dynamic and EOS experiments

6. Solid State Physics

- Los Alamos Neutron Scattering Center (LANSCE)

- Raman Spectroscopy Lab

-Electron Microscopy Lab

7. Weapon's effects and simulation

-MIDI Rail Gun

-High Power Microwave (HPM)/Electromagnetic Pulse (EMP)

Facility

-Los Alamos Critical Assemblies Facility - especially the Comet, Honeycomb, Thor Core, Mars, and Planet assemblies

- Weapons Neutron Research (WNR) Facility

- Ground Test Accelerator (GTA)

- Nuclear Test Film Vault

\section{B. Conceptual Design and Assessment}

1. Mission definition 
- Center of National Security Studies

2. New concept formulation

3. New designs

4. Systems testing techniques

-Device Assembly Facility

5. Tradeoff and evaluations

-Non-Destructive Test (NDT) Facilities

C. Computations and Modeling

1. Computational Requirements and Capabilities Acquisition - Central Computing Facility (CCF) - Central Mainframes and support labs

-Advanced Computing Lab

2. Code Development

-Distributed Computer Network and Nodal Complex

3. Risk Assessment Methodology

-Advanced Simulation Lab

\section{Mathematics}

- Center for Non-linear Studies

\section{Systems Cluster}

\section{A. Engineering Science and Technology}

1. Safing, Arming, Fusing, and Firing Subsystems

-Explosive Detonator Facilities (TA-22)

2. Command and Control

3. System Performance Instrumentation Technology -Rack Assembly and Alignment Complex (TA-60)

4. Standardization, Producibility Development - Metrology Lab - Nondestructive Testing and Evaluation (TA-8)

5. Design, Development and Manufacturing - Weapons Subsystems Laboratory (Ice House)

\section{B. Components}

1. Electronic and Photonic Components

2. Mechanical Components 


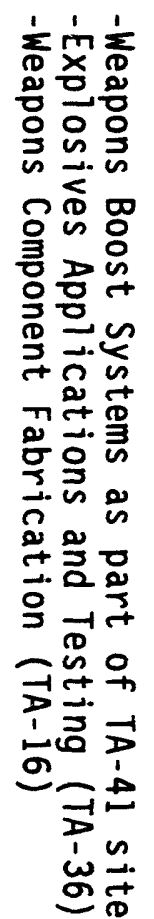




\section{LLNL INPUT FOR FACILITIES LISTING}

\section{Weapons Materials Cluster}

\section{A. Chemistry and Materials Element}

1. Metallurgy

-B321 - Materials Fabrication Cumplex. This complex supports R\&D and fabrication in a variety of technologies that include: optics inspection, optics coating, glass laboratory, metal finishing, repairs, precision machining, 1ap/miniature machining, ceramics, welding, sheet metal, tool and cutter grinding center, electron beam welding, general and precision assembly, inspection, heat treat, spin press, special materials machining, and precision turning.

2. Ceramics

-B321 - Materials Fabrication Complex. (See I.A.1)

3. Organics

4. Compatibility and Aging

5. Analysis

6. Materials Supporting Facilities and Capabilities -B321 - Materials Fabrication Complex. (See I.A.1)

-B329 - Laser Welding. This facility supports all Laboratory programs where the fabrication of components and assemblies require a high degree of accuracy and where other techniques are impractical or unavailable.

-B343 - High Pressure Laboratory. The High Pressure Laboratory includes testing, evaluation, and hardware development in support of all general Lab-wide programs and provides high pressure gas transfer support for the LLNL Nuclear Test Program. The facility also supports other DOE facilities that do not have high-pressure capabilities.

B. Explosives (includes HE/IHE R\&D, Advanced explosive research and detonation systems R\&D)

1. Explosives: Basic and Applied R\&D [includes HE, IHE, and new reactive materials/super explosives] 
-B806, B807, B809, and B828 - High Explosives Machining Facility. These buildings support the Weapon Program's requirements for high explosive machining.

-B809, B239, and B327 - Computed Tomography (CT). The charter for the CT Facility is to have at the Laboratory a broad range of CT scanners for 2- and 3-D imaging required to solve the wide range of programmatic material/component inspection and assembly problems.

-B809, B823, and B823 - Radiation Applications. The Radiation Applications facilities in Buildings 809 and 823 provide both high and medium energy $x$-ray radiography, film processing, and real-time imaging for high explosive billets, components, and assemblies. The facility is unique in its ability to provide radiography of high explosives.

-B813, B814, B818, B840, and B874 - Change House, Shipping and Receiving, Explosives Study and Mechanical Shops, storage/handling of high explosives.

- В M- $1,2,3,4,7,8,9,21,22,23,24,30,31,32,34,35$, $37,52,70,71,72,808,810 \mathrm{Al}, \mathrm{A2}, 810 \mathrm{~B} 1$ \& $\mathrm{B2}, 817 \mathrm{~A} 1,817 \mathrm{E}$, $822 A-D, 828,829-1,2$. Storage of high explosives.

-B251 - Heavy Element Facility. This facility provides research areas for conducting experiments using transuranic elements.

-B801 - Explosives Testing Facility (FXR). The Explosives Testing Facility houses state-of-the-art capabilities used to diagnose several aspects of high explosive events. It is currently the mainstay in the hydrodynamics testing aspects of the LLNL nuclear weapons program. Diagnostics include an extensive suite of high speed photography, velocimetry, digitizers/shorting pins, radiography (by the Flash X-Ray accelerator and by portable $x$-ray generators), and recent, significant enhancements (gamma ray camera and IC camera) to both radiographic and photographic methods.

- B802 - High speed camera repair and storage facility. Until the reconfiguration of $B 850$ is complete, this facility is in an interim status as a means to test and repair the several high speed cameras, along with related hardware and systems. In the absence of this capability, such testing and repair must be done in the bunkers and necessarily interferes with the normal operations and conduct of experiments.

-B806, B807, B809, and B828 - High Explosives Machining Facility. These buildings support the Weapons Program's requirements for high explosive machining. 
-B805, B810, B817, and B829 - High Explosives and Isostatic Press. This facility is used for preparing explosive charges in various configurations and for assembly of explosive charge with metal and detonators into devices for hydrodynamic studies and other special explosives operations. In addition bulk materials and mock HE for isostatic pressing and/or machining are prepared in this facility.

\section{Detonation Systems}

\section{Special Nuclear Materials}

1. Metallurgy

-B332 - Plutonium Building. Current programmatic activities include some device fabrication, development of plutonium -bearing engineering assemblies, and development of improved or unique plutonium fabrication techniques, such as near net-shape casting, and applied and basic research in plutonium metallurgy. In addition, the demonstration of pyrochemical plutonium processes are performed in support of Complex Reconfiguration. In support of the plutonium R\&D activities, the facility maintains the safe and secure storage of plutonium and other SNM.

\section{Processing}

-B321 - Materials Fabrication Complex. (See I.A.1)

-B332 - Plutonium Building. (See I.C.1)

3. Waste Minimization R\&D

-B332 - Plutonium Building. (See I.C.1)

4. Special Operations

-B332 - Plutonium Building. (See I.C.1)

-B151 and B154 - Nuclear Chemistry Buildings. These facilities support the development and application of radiochemical and isotopic techniques to conduct a broad range of analytical measurements and scientific studies. The applied research and development programs include support for the US and UK nuclear testing programs, support for the DoD weapons effects testing, environmental science and monitoring, nuclear waste disposal, and technology for the safeguarding of special nuclear materials. In addition, the buildings house facilities for basic research in low- and medium nuclear physics, in geochemistry and radiochemistry, and in inorganic and physical chemistry. 


\section{Tritium}

-B331 - Tritium Facility. Since July 1991 its principle mission has been inventory reduction toward a goal of 1 gram or less. Within this constraint the focus of operations are Low Level Radioactive Waste characterization, packaging, and disposal.

\section{I. Design Sciences and Capabilities Cluster}

\section{A. Physics}

1. Hydrodynamics

-B809, B823, and B823 - Radiation Applications. (See I.B.1)

$-8813, B 814, B 818, B 840$, and B874 - Change House, Shipping and Receiving, Explosives Study and Mechanical Shops, storage/handling of high explosives. (See I.B.1)

-B M-1, 2, 3, 4, 7, 8, 9, 21, 22, 23, 24, 30, 31, 32, 34, 35, $37,52,70,71,72,808,810 \mathrm{Al}, \mathrm{A2}, 810 \mathrm{~B} 1$ \& $\mathrm{B} 2,817 \mathrm{~A} 1,817 \mathrm{E}$, $822 A-0,828,829-1,2$. Storage of high explosives. (See I.B. 1)

-B251 - Heavy Element Facility. (See I.B.1)

-B801 - Explosives Testing Facility (FXR). (See I.B.1)

-B802 - High speed camera repair and storage facility. (See I.B.1)

-B806, B807, B809, and B828 - High Explosives Machining Facility. (See I.B.1)

-B805, B810, B817, and B829 - High Explosives and Isostatic Press. (See I.B.1)

\section{Neutronics}

-B132S - Nuclear Test Technology Complex. This new facility, which is nearly ready for occupancy, will consolidate existing personnel and diagnostics development activities currently located in several buildings and trailers. It will provide a state-of-the-art high technology environment to support research into new measurement technologies and new initiatives in experimental science. While preserving and maintaining core testing technologies and capabilities, a main function will be the converting of dual-use technologies, originally developed to diagnose nuclear tests, to address national and/or industrial problems including those in non- 
proliferation, counter proliferation, remote sensing, high bandwidth communication, and photonics.

3. Plasma Physics and Radiation Transport

-B141 - Pulsed Power Laboratory. The Pulsed Power Laboratory provides a capability to conduct high quality research and development of technologies which support existing and emerging programmatic pulsed power needs.

4. Atomic and Nuclear Physics

5. Materials Dynamics and EOS

6. Solid State Physics

7. Weapon's effects and simulation

-B132S - Nuclear Test Technology Complex (See II.A.7)

\section{B. Conceptual Design and Assessment}

1. Mission definition

2. New concept formulation

3. New designs

4. Systems testing techniques

5. Tradeoff and evaluations

\section{Computations and Modeling}

1. Computational Requirements and Capabilities Acquisition

-B113, B115, and B117 - Livermore Computing Complex. The Secured Computing Facility and the Open Computing Facility are housed in this three building complex. The equipment residing in the complex represents the latest technology in scientific computing, networking, storage, and output. The facilities also provide an environment for software development activities. Some of the activities include: application software development, value added extensions to commercial/standard software products and general computer utility software development.

2. Code Development

-T1205 - Computational Mechanics. This facility provides space to research, develop, and maintain the mechanical engineering computer software for solid, structural, fluid 
mechanics and heat transfer, as well as mesh generation and graphic post processors.

-B113, B115, and B117 - Livermore Computing Complex (See II.C.1)

3. Risk Assessment Methodology

\section{Mathematics}

\section{Systems Cluster}

\section{A. Engineering Science and Technology}

1. Safing, Arming, Fusing, and Firing Subsystems

2. Command and Control

3. System Performance Instrumentation Technology

-B231 - High Bay. Principal uses are assembly, testing, and fabrication of device systems event hardware prior to shipping to the EG\&G ATLAS facility at North Las Vegas, Nevada.

- Tonopah Test Range Radiation Applications (TTR). The Radiation Applications facility at Tonopah Test Range provides field radiography with either radioisotope sources or the transportable LINAC.

4. Standardization, Producibility Development

5. Design, Development and Manufacturing

-B239 - Radiation Applications. The Radiation Applications facility in B239 provides both high and medium energy $x$-ray radiography, film processing, real-time imaging and image analysis.

-B327 - Radiation Applications. The Radiation Applications facility in B237 provides capability with low and medium energy film, digital and real time radiography, film processing and image analysis, with a function complementary to that in B239.

-B334 - Hardened Engineering Test Building. This unique facility can have plutonium bearing NELAs for experimental purposes. The experiments can be on radiation measurements such as intrinsic radiation, or on environmental tests, including thermal shock and cycling, vibration, impact and mechanical shock.

-B809, B239, and B327 - Computed Tomography (CT) (See I.B.1) 
B. Components

1. Electronic and Photonic Components

2. Mechanical Components 


\section{SNL INPUT FOR FACILITIES LISTING}

\section{Meapons Materials Cluster}

\section{A. Chemistry and Materials Element}

Virtually every facet of our mission involves advanced technical work in the area of Chemistry and Materials and, in this sense, the Laboratories, as a whole, are devoted to materials science and engineering. Many, if not all of the facilities listed as important in the areas of Component Development and Explosives are also vital to the technology base in Chemistry and Materials.

$$
\begin{aligned}
& \text {-Building } 805 \text { - Research and Standards Laboratory. } \\
& \text {-Building } 806 \text { - Research and Development Laboratory. } \\
& \text {-Building } 807 \text { - Research and Development Laboratory. } \\
& \text {-Building } 858 \text { - Microelectronics Development Laboratory. } \\
& \text {-Building } 860 \text { - Environmental Testing Laboratory. } \\
& \text {-Building } 878 \text { - Process Development Laboratory. } \\
& \text {-Building } 891 \text { - Component Development Laboratory. } \\
& \text {-Building } 893 \text { - Compound Semiconductor Research Lab. } \\
& \text {-Building } 894 \text { - Power Development Laboratory. } \\
& \text {-Building } 905 \text { - Explosives Components Facility (ECF). } \\
& \text {-Building } 907 \text { - Performance Testing Laboratory. } \\
& \text {-Building } 915 \text { - Component Development \& Testing Lab. } \\
& \text {-Building } 919 \text { - Explosive Devices Building. } \\
& \text {-Building } 922 \text { - Explosive Devices Development Laboratory. } \\
& \text {-Building } 935 \text { - Neutron Generator Test Facility. } \\
& \text {-Building } 940 \text { - SCB Testing \& Explosive Ignition Lab. }
\end{aligned}
$$

Many of the facilities that are important to the work in tritium chemistry and storage, at our site near Livermore, should also be added to this list. In each case, these facilities provide data or programmatic support or both to our efforts in materials science. Another facility, in Albuquerque, also provides important support. 
-Building 828 - Transducer Evaluation and Calibration. This is a very old and completely substandard structure; however, it has been pressed into service to house important capabilities in the area of mechanical behavior characterization.

Many of these installations will require ES\&H enhancements or, alternatively, construction of new structures beyond construction of the ECF which has already been discussed.

-Building 897 - Integrated Materials Research Laboratory. The Integrated Materials Research Laboratory (IMRL), under construction, will consolidate a number of important materials science capabilities and create a highly integrated research environment that will be focused on materials development, characterization, and processing technologies; constitutive theory; computer modeling; and advanced concepts.

- Processing and Environmental Technologies Laboratory (PETL). The PETL will also provide an alternative to older, substandard, existing installations and will consolidate a large number of widely scattered capabilities focused on the development of technologies for waste management, handling, transportation, minimization, detoxification, and disposal.

\section{B. Explosives}

As previously indicated, many of the important facilities in this area are currently housed, in Tech Area II, in some of oldest structures remaining in use at the Laboratories; structures which predate both Sandia Corporation and weapons assembly at Pantex. These structures are severely obsolete and grossly inadequate and, in this context, the most important facility in this technology area is a new facility that is only now being constructed.

-Building 905 - Explosives Components Facility (ECF). The ECF will have a key role in the development and maintenance of the stockpile in the areas of advanced component development and prototyping; Stockpile Improvement Programs (Sips); advanced disablement and enhanced use control; research and development necessary for increased privatization; product acceptance testing; neutron generator research, development, and testing; reliability and surety studies; optical ordnance development to enhance weapons safety; and safety evaluation. The facility will represent a major enhancement of current capability, as well as providing additional capabilities not presently available.

Construction and beneficial occupancy of the ECF is essential; however, in the near term, a number of older, marginal, facilities must remain in use and continue to play important roles.

-Building 907 - Performance Testing Laboratory. This is the primary facility for general performance testing of explosives and components.

-Building 915 - Component Development \& Testing Lab. The primary function 
of the facility is research and development associated with explosive components and propellant devices. A secondary function is specialized testing to determine the response of a wide range of energetic materials to abnormal environments.

-Building 922 - Explosive Devices Development Laboratory. This building houses a world class explosive dynamics and spectroscopy laboratory, with capabilities for real-time monitoring of reacting energetic materials. Many of the spectroscopic techniques are specifically tailored for studying explosive phenomena and addressing basic questions of energetic material safety and performance. The facility can employ various initiation mechanisms, including conventional detonators, planar shock waves from projectile impact using a light-gas gun, high heating rate experiments using a pulsed dye laser and direct optical initiation.

-Building 940 - SCB Testing \& Explosive Ignition Lab. This facility allows specialized and controlled testing of semiconductor bridge (SCB) prototypes. It also houses a 400 watt $\mathrm{Nd}-\mathrm{YAG}$ laser for low-energy, explosive ignition studies; a light electronic area for testing firing sets and other electronic assemblies; and photomicroscopy equipment for examination and post test analyses.

Similar to the situation with our Component Development efforts, the data acquired through the use of our extensive testing capabilities in the Coyote Canyon Test Complex, at the Kauai Test Facility, on the Tonopah Test Range, at the Nevada Test Site, and in our Tech Areas III, IV, and V are critical to our work in Explosives; however, as was the case with Component Development, these capabilities will be more appropriately addressed under System Engineering and Integration.

\section{Special Nuclear Materials}

Sandia National Laboratories do not, at this time, have any facilities that are of particular importance in this area.

\section{Tritium}

Most of the Laboratories' work in this area is located on our site near Livermore, California. Although long-term options for approaching this work are under development, a number of facilities should definitely be considered as currently important facilities.

-Building 913 - Welding and Assembly.

-Building 914 - Applied Mechanics Laboratories.

-Building 916 - Physics and Materials.

-Building 923 - Radiography Facility.

-Buildings 940 through 943 - Defense Engineering Laboratory. 
-Building 966 - High Pressure Test Facility.

-Building 968 - Tritium Research Laboratory.

In addition, there are a number of facilities, beyond the site infrastructure itself, that provide significant levels of support to these operations.

-Buildings 955 and 956 - Environmental Testing Labs.

-Building 961 - Decontamination and Storage Facility.

-Building 967 the TRL Offices

-Mobiles M03, M14, M23, M24, M26, M29, M40, \& M41-ES\&H and Facilities Support. Please note that many of the most important support functions on this site, ES\&H and Facilities Support, are located in mobile buildings that are temporary at best and require constant maintenance. There is one facility in Tech Area IV in Albuquerque that must be considered important in this area, due the tremendous potential cost savings and operational safety benefits that could be realized through its use.

-Building 963 - Repetitive High Energy Pulsed Power. This facility, known as the RHEPP, is designed to demonstrate a lower cost, high average power, particle beam technology for a number of possible future applications, specifically including the production of weapons tritium without the use of a reactor.

\section{Design Sciences and Capabilities Cluster}

\section{A. Physics}

As indicated in the program element plan for this area, Sandia National Laboratories engage in a wide range of activities in this discipline. Most of this work involves component or weapons effects physics; however, there are a number of facilities that should be considered important to these efforts.

- Building 858 - Hicroelectronics Development Laboratory. This facility is used for the fabrication and, study of radiation hardened microelectronics and the physics underlying their performance, design, and manufacturing processes.

-Building 893 - Compound Semiconductor Research Lab. This facility is used to investigate the physics of compound semiconductors and lattice structures and to fabricate optoelectronic and digital compound semiconductor devices for both research and prototyping purposes.

-Building 970 - Hermes III, SABRE, and Saturn. Hermes III is primarily operated for nuclear effects testing; however, it is also the primary test bed for the development of intense gamma ray simulators and is very important to the development of both the Externally Driven Nuclear Assembly (EDNA) and the Laboratory Microfusion Facility (LMF), both of which will reduce our reliance on underground testing. In the same 
building, SABRE is also developing technology that is an important step on the road to the LMF and Saturn is the world's most energetic pulsed $x$-ray source. By driving imploding plasmas for $x$-ray production, Saturn contributes substantially to our threat assessment mission in $x$-ray lasers and to radiation flow studies for both inertial fusion and weapons physics.

-Building 983 - Particle Beam Fusion Accelerator II (PBFAII). This is the only facility in the world with the potential to drive inertial confinement fusion targets with light ion beams. In this context, it is a unique and important asset in the development of an affordable approach to inertial fusion either for power production or to reduce reliance on underground testing.

-Building 6588 - Annular Core Research Reactor (ACRR). The ACRR is a pool-type reactor that is capable of both pulsed and steady state operation and tailored transient rod withdrawal. In addition to its primary function in testing electronics, materials, and fissile components, the facility is al so used for research associated with reactor safety and FALCON.

-Building 6593 - Sandia Pulsed Reactor III (SPRIII). The SPRIII is a fast burst reactor with both pulsed and steady state capabilities. In addition to meeting high neutron fluence or pulsed high dose requirements for the testing of electronics, it is also important in research associated with FALCON.

Several of our facilities on the Nevada Test Site should also be considered important, particularly with regard to component physics and weapon effects physics.

- Building CP1 - Area 6 Control Point. There are two Sandia facilities in this building. The Sandia Monitor Room houses area radiation monitors, geophone and seismic monitoring equipment, and computer systems necessary for monitoring and control functions. These facilities are used by the DOE Test Controller during every event on the site and provide important support to Sandia, LANL, LLNL, and DNA activities during and after every event. The Sandia Arming and Firing Laboratory, in the same building, is used for the initial assembly, checking, and calibration of most of the arming and firing equipment, including the neutron generators, used at the NTS. These are unique capabilities at the NTS and are necessary to support the testing program.

- Building CP14 - Control Point Communications. This unique facility links the monitoring, control, and recording systems near the Area 12 Test Complex with the Area 6 Control Point.

-Building 12-909 - Area 12 Test Complex. This building houses data recording systems that support all underground nuclear weapons effects testing at the NTS. It supports all three of the DP Laboratories and the DNA. 


\section{B. Conceptual Design and Assessment}

Taking a broad view of this program element, few areas of endeavor illustrate the interdependency of our operations as clearly as this one. Although only a few facilities can be exclusively identified with this area, virtually every technical structure at the Laboratories contributes to these efforts. As is the case with many other program element areas, particularly Component Development and Chemistry and Materials, data acquired through the use of virtually all of our extensive testing capabilities in the Coyote Canyon Test Complex, at the Kauai Test Facility, on the Tonopah Test Range, at the Nevada Test Site, and in our Tech Areas III, IV, and V are critical to our work in Advanced Weapons Design. Although most of these capabilities will be more appropriately addressed under System Engineering and Integration, there are some facilities that should be addressed or highlighted under this program element.

- Building 836 - Weapons Systems Engineering. This structure houses and supports most of our key technical staff in the weapons area.

-Buildings 940 through 943 - Defense Engineering Laboratory. These facilities, on our site near Livermore, house key personnel with regard to our interface with Lawrence Livermore National Laboratory.

There are several facilities that supply long range input to the design of both nuclear and nonnuclear components and are, thus, important to this program element.

- Building 868 - Systems Research Laboratory. This facility houses the Systems Research Center, which is the organization responsible for Foreign Technology Assessment in support of Defense Programs in the areas of Nuclear Weapon Design, Dismantlement, and Prol iferation. Space limitations in Building 868 have already forced this organization to begin using space in Building 890, the Instrumentation Systems Laboratory; and the security requirements for this group make completing the construction of Building 810, the Center for National Security and Arms Control, an essential priority.

-Building 890 - Instrumentation Systems Laboratory. The design of this building, which is also important to the Laboratories' efforts in Foreign Technology Assessment, incorporates a number of physical security features that make it a particularly valuable facility.

-Building 880 - Computing and Special Project. In addition to the fact that much of the Systems Research Center's work in Nuclear Weapons Surety is housed in this older structure, much of our on site computing support function is also located here and, thus, this old structure is doubly important to Advanced Weapons Design.

-Buildings 871, 872, and 888 - Electromagnetic Analysis and Test Facilities. As increasing emphasis is placed upon the EM environments that may be encountered by weapons or their delivery systems, these 
facilities have become increasingly important.

- Building 963 - Collgun Electromagnetic Launcher. This facility in Tech Area IV in Albuquerque is one of several that are being used to investigate, demonstrate, and assess the threat posed by the use of electromagnetic guns as a means of accelerating projectiles to velocities in excess of those obtainable with chemical or gas gun technologies. This is a unique and important technology with additional potential in applications ranging from long range strike weaponry to the launching of small satellites for either military or commercial purposes.

-Building 970 - Saturn. This facility, also in Tech Area IV in Albuquerque, is operated for nuclear weapon effects testing and for driving imploding plasmas for $x$-ray production. It is critical to our threat assessment mission in $x$-ray lasers and to radiation flow studies for both inertial fusion and weapons physics.

- Weapon Evaluation Test Laboratory - This facility, at Pantex, provides a wide range of important product performance data that can be of great value in even the earliest stages of weapon design, particularly as we increase our already significant focus on designing for the entire life cycle of the product.

- The Tonopah Test Range (TTR). The TTR is truly unique with regard to providing the opportunity for field scale testing of both systems and concepts. These efforts have implications for the design of virtually all components, both nuclear and nonnuclear. Of particular current value are capabilities for testing in the areas of stealth and penetration technologies. The Davis Gun capabilities are of particular current importance to both the DOE and DOD because of the increasing possibility that the capability to attack deeply buried targets will be required.

Again, this is certainly not a complete listing. For example, Building 962 , the Strategic Defense Facility has not specifically been mentioned; however, it does provide important support to the operations in both Building 963 and Building 970. In addition, there is one new facility, the construction of which is deemed to be important to sustaining the work of the Systems Research Center in the area of Foreign Technology Assessment.

- Building 810 - Center for National Security \& Arms Control. This facility will serve as the focus for national security, verification, and arms control activities that are rapidly evolving in response to both changes in the international scene and advances in technology. The structure itself will incorporate an array of advanced security features and, by housing a number of technically related operations, will encourage both efficiency and a beneficial synergy.

\section{Computations and Modeling}

There are a number of facilities at the Laboratories that are currently of noteworthy importance in this area. 
-Building 806 - Research and Development Laboratory. This building houses many of the operations associated with the further development of massively parallel computing.

-Building 880 - Computing and Special Projects. As indicated previously under Advanced Weapons Design, much of our onsite computing support function is centered in this building. Originally built in 1953 to serve in essentially a warehouse capacity, the structure has been repeatedly modified and upgraded through the years and now houses a wide variety of laboratory, engineering, technical support, and administrative functions. The structure is not, however, opt imally efficient for computer operations and a new facility, the Computer/CAE Facility, has been proposed to consolidate computing operations in a more appropriate environment that has been specifically designed to meet modern computing needs.

-Building 980 - Particle Beam Fusion Office Facility. For the near term, prior to construction and beneficial occupancy of the Computer/CAE Facility, much of the Laboratories' scientific computing capabilities are being housed in this structure, as an interim alternative to Building 880 .

-Building 912 - Computer Center. Although Sandia is completing the consolidation of our computing capabilities to our Albuquerque site, this facility, in Livermore, still provides important computing capabilities.

Much of the Laboratories work in the area of Computation and Modeling is directed toward the application of advanced technologies to the challenges associated with manufacturing and production, transportation, safety, security, and environmental protection and restoration. The use of advanced computing in the operation and control of robotic systems is of critical interest.

-KAFB Building 20245 - The 01d Air Force Commissary. This leased facility, originally built as a commissary for the USAF, has been remodeled to house a wide variety of DOE, USAF, and Sandia operations, including our Center for Intelligent Systems and Robotics. Although tolerable as a temporary bridge to more permanent facilities, the commissary was not designed for and is not efficient for the interactive development of these technologies. A new facility, the Robotics Manufacturing Science and Engineering Laboratory (RMSEL), is being funded as a more appropriate permanent home for our efforts in robotics.

The mission of our Center for Transportation Systems is to develop and apply advanced systems solutions to national transportation problems. More specifically, our Defense Transportation Programs provide technology to ensure the safe and secure transportation of nuclear weapons and weapon materials. This mission is pursued through the development of computing and modeling technologies in the areas of intelligent systems, mobile robotics, sensor development and application, command and control architectures, the human/machine interface, and fieldable systems for applications that include command and control, image processing and simulation, and expert systems. 
The Center utilizes a variety of facilities, including major buildings, mobile and permanent trailers, open area test ranges, high-bay laboratories, and bunkers. Two of these facilities are important to computing and modeling.

-Building 821 - Nuclear Safeguards Security Laboratory. Butlding 821 is a relatively modern structure that houses office space, general and special laboratory space, and computer space, all of which is necessary to the operations of the Center.

-Land Use Permit KAFB-R-OG-87-1 - Robotlc Vehicle Range (RVR). Tine RVR is a two hundred acre open range for testing vehicles by remote control. A new control room, with driving stations for the robotic vehicles, makes possible the real-time navigation of these intelligent systems, allows the interactive evaluation of control systems, and makes this an important facility with respect to the development of computing and modeling technologies.

As indicated previously, two new facilities will also be very important to our computing and modeling operations.

- Computer/CAE Facility. This facility will provide an operational environment that is conducive to modern, efficient, computer support and a physical environment that safeguards the substantial capital investment that these systems represent.

- Robotics Manufacturing Science and Engineering Laboratory. This facility will allow an interactive approach to the development of intelligent systems and permit a substantial acceleration in the evolution of these technologies.

\section{Mathematics}

\section{Systems Cluster}

\section{A. Engineering Science and Technology}

One of Sandia National Laboratories' greatest strengths is System Engineering and Integration. As indicated previously, our success in developing a record of excellence in systems integration has truly been a fundamental factor in our success in the Nuclear Weapons Program as a whole. This is al so the most highly integrated area of endeavor on the site, with virtually every one of our facilities making an important contribution in this area. For the purposes of this exercise, however, we will attempt to communicate an understanding of this program element along the lines of three hypothetical subelements.

Design, Engineering, \& Computation

Prototype Development

Testing and Evaluation 
These three subelements are valuable in describing the types of functions that constitute System Engineering and Integration. Although they are, in theory, the fundamental parts of a sequential process, it should be noted that they in no way represent sequential phases of a reliably linear process in actual practice. In reality, System Engineering and Integration is a challenging, nontrivial, nonlinear, tterative process in which information revealed anywhere in the process, in any one of these functional subelements, can form the basis for exploratory investigations that can and often do proceed in a wide range of directions.

With these points made, those facilities that contribute to the design, engineering, and computation function gene, rally form the guiding core of System Engineering and Integration.

- Building 802 - Administration and Development Labs. This older structure houses a substantial portion of the engineering records function for the Nuclear Weapons Program.

-Building 804 - The Technical Library. This facility is important to virtually every technical endeavor at the Laboratories.

-Building 821 - Nuclear Safeguards Security Laboratory. Building 821 is a relatively modern structure that houses the Center for Transportation Systems.

-Building 836 - Weapons Systems Engineering. This structure houses and supports most of our key technical staff in the weapons area, including much of our engineering methods and procedures functions. It al so houses some key computer support functions, including a significant portion of our design workstations.

-Building 859 - CAE and Network Laboratories. This facility keeps the design and engineering processes current by providing the capability to monitor, investigate, and rapidly implement new and advanced CAE and Network software and systems.

-Building 880 - Computing and Special Projects. This structure, originaliy a warehouse, currently houses the bulk of our on-site computer support function. The structure is not, however, optimal for computer operations and a new facility, the computer/CAE Facility, has been proposed to consolidate computing operations in an appropriate facility that has been designed for a modern computing environment.

-Building 890 - Instrumentation Systems Laboratory. The design of this building, which is also important to the Laboratories' efforts in foreign Technology Assessment, incorporates a number of physical security features that make it a particularly valuable facility.

-Building 892 - Military Liaison and Training. In addition to the Laboratories' Defense Programs Division and Sector Offices and our 
military liaison functions, this large and very old structure houses the bulk of our design workstations and engineering drawing functions, a portion of our engineering methods and procedures functions, the Network Center for intersite and intrasite CAD communications, the Image Management System, and a portion of our records and configuration management functions.

- Butlding 980 - Particle Beam Fusion Office Facility. For the nearterm, prior to construction and beneficial occupancy of the Computer/CAE Facility, much of the Laboratories' scientific computing capabilities are being housed in this structure, as an interim alternative to Building 880 .

As discussed under Computation and Modeling, the Laboratories are firmly convinced that the development and use of robotic systems has the potential for leverage for both Defense Programs and the Strategic Industrial Base.

-KAFB Bullding 20245 - The 01d Air Force Commissary. As previously indicated, this leased facility houses our Center for Intelligent Systems and Robotics. Although tolerable as a temporary bridge to more permanent facilities, the commissary was not designed for and is not efficient for the interactive development of these technologies. A new facility, the Robotics Manufacturing Science and Engineering Laboratory (RMSEL), is being funded as a more appropriate permanent home for these efforts.

Also as indicated previously, two new facilities will be very important to a wide cross section of our operations, including System Engineering and Integration.

-Computer/CAE Facility. This facility will provide an operational environment that is conducive to modern, efficient, computer support and a physical environment that safeguards the substantial capital investment that these systems represent.

- Robotics Manufacturing Science and Engineering Laboratory (RMSEL). This facility will allow an interactive approach to the development of intelligent systems and permit a substantial acceleration in the evolution of these technologies.

Due to the nature of the design process, a number of facilities on our site near Livermore are of truly critical importance in the area of System Engineering and Integration, particularly on projects involving Lawrence Livermore National Laboratory.

-Butlding 910 - Weapons Laboratory.

-Building 912 - Computer Center.

-Buildings 940 through 943 - Defense Engineering Laboratory. The extensive use of developmental prototyping is increasing, in both Defense 
Programs and the Nation's Strategic Industrial Base, as an outgrowth of the need to bring engineering and design into more direct and intimate contact with the constraints and opportunities of the actual manufacturing and production process. Sandia National Laboratories have long been known for excellence in our rapid and system level prototyping capabilities. A number of our facilities are of truly national importance with regard to preserving and properly disseminating these skills. Many of these facilities are, of course, aiso important in other areas or to other functions.

-Buildings 840,841 , and 842 - Developmental Fabrication Shops. These older facilities, housing a wide array of fabrication functions, are the hub of our heavy prototyping capabilities. They provide a variety of necessary and, in some cases, unique services, including, but not limited to, coils and transformers, casting, machining, tooling, welding, and flame spray.

-Building 858 - Microelectronics Development Laboratory. Silicon microelectronics projects are currently underway in the areas of radiation hardened integrated circuits, ferroelectric nonvolatile memories, smart sensors, advanced packaging, and smart micromechanical devices.

-Building 865 - Wind Tunnel Experimental Facility. This facility provides a unique set of capabilities, in the areas of aerodynamics and basic fluid mechanics. These capabilities are essential as a support base for a wide variety of prototyping activities.

-Building 878 - Process Development Laboratory (PDL). This facility is truly critical to a wide range of prototyping, particularly in the areas of electronics, encapsulation, ceramics, mechanical processes and engineering, and component design support.

-Building 891 - Component Development Laboratory. This building houses a wide variety of capabilities that are specialized, unique to nuclear weapon applications, and not available in the commercial sector.

-Building 893 - Compound Semiconductor Research Lab. The Compound Semiconductor Research Lab (CSRL) is vital to prototyping in the areas of high speed electronics, microwave control circuits, laser arrays, IR detectors, and nonvolatile memories.

- Building 894 - Power Development Laboratory. This facility is the hub of activities directly associated with the design, development, and prototyping of thermal batteries, lithium batteries, and parachutes.

-KAFB Building 20245 - The 01d Air Force Commissary. This facility is also important to the development of prototypes in the areas of robotics and intelligent systems.

A number of existing facilities in Livermore are also important contributors in 
this area.

-Building 912 - Computer Center.

-Building 913 - Welding and Assembly.

-Building 914 - Applied Mechanics Laboratories.

-Building 916 - Physics and Materials.

-Building 923 - Radiography Facility.

-Buildings 940 through 943 - Defense Engineering Laboratory.

-Building 966 - High Pressure Test Facility.

There are also several facilities that are new, proposed, or under construction and will be important improvement or replacement capabilities in prototype development. Many of these facilities are also important in other areas as well.

-Building 897 - Integrated Materials Research Laboratory. The Integrated Materials Research Laboratory, under construction, will consolidate a number of important materials science capabilities,

-Building 905 - Explosives Components Facility (ECF). The ECF will have a key role in the development and maintenance of the stockpile in tire areas of advanced component development and prototyping; Stockpile Improvement Programs (SIPS); advanced disablement and enhanced use control; research and development necessary for increased privatization; product acceptance testing; neutron generator research, development, and testing; reliability and surety studies; optical ordnance development to enhance weapons safety; and safety evaluation.

-Robotics Manufacturing Science and Engineering Laboratory (RMSEL). This facility will, like the 01d KAFB Commissary which it will replace, provide important prototype development capabilities.

- Processing and Environmental Technologies Laboratory (PETL). The PETL will also provide an alternative to older, substandard, existing installations and will consolidate a large number of widely scattered capabilities focused on the development of technologies for waste management, handling, transportation, minimization, detoxification, and disposal.

The guidance provided by Testing and Evaluation activities is essential to the Laboratories' overall success in System Engineering and Integration. Although some form of testing and evaluation is routinely done in virtually every one of our facilities on a daily basis, there is also a very wide range of facilities that specifically support these activities.

In our Tech Area I: 
- Building 805 - Research and Standards Laboratory. This facility provides necessary support in the areas of standards and calibration.

- Building 807 - Research and Development Laboratory. This building houses the High Voltage Pulse Facility, Transformer Development Laboratory, and Zetatron Test Facility.

-Building 808 - Test Assembly Laboratory. All of our flight systems are assembled and tested in this building; however, this is an older structure and the quality and quantity of space currently available could impose significant restrictions on our programs in the future.

-Building 827 - Weapons Production Primary Standards Lab. This facility, still under construction, will provide a wide range of necessary capabilities in the areas of standards and calibration.

-Building 828 - Transducer Evaluation and Calibration. This is an old and substandard structure; however, it has been pressed into service to house important capabilities in the area of mechanical behavior characterization.

-Building 860 - Environmental Testing Laboratory. This is also an older facility that provides important environmental testing capabilities to a number of efforts.

-Building 865 - Wind Tunnel Experimental Facility. This facility provides unique experimental capabilities, in the areas of aerodynamics and basic fluid mechanics, for weapon system design and a variety of other research and development applications that include nuclear weapon stockpile evaluation, research in aerodynamics and fluid mechanics, guidance for building computational aerodynamics models, and validation of computational aerodynamics codes.

-Buildings 871, 872, and 888 - Electromagnetic Analysis and Test Facilities. As increasing emphasis is placed upon the EM environments that may be encountered by weapons or their delivery systems, these facilities have become increasingly important.

In our Tech Area II:

-Building 905 - Explosives Components Facility (ECF). Many of the important facilities in Tech Area II are currently housed in some of oldest structures remaining in use at the Laboratories, structures which predate both Sandia Corporation and weapons assembly at Pantex. These structures are severely obsolete and grossly inadequate. The ECF, only now being constructed, will replace many of these structures, as well as play a key role in the development and maintenance of the stockpile in the areas of advanced component development; Stockpile Improvement Programs (Sips); advanced disablement and enhanced use control; research and development necessary for increased privatization; product acceptance testing; neutron generator research, development, and testing; reliability and surety studies; optical ordnance development to enhance weapons 
safety; and safety evaluation.

-Building 907 - Performance Testing Laboratory. This is currently the primary facility for general performance testing of explosives and components.

-Building 915 - Component Development \& Testing Lab. The primary function of this facility is research and development associated with explosive components and propellant devices. A secondary function is specialized testing to determine the response of a wide range of energetic materials to abnormal environments.

-Building 919 - Explosive Devices Building. Specialized testing of power sources is currently conducted in this structure; however, the structure is obsolete and inadequate and this function will be relocated to the ECF.

-Building 922 - Explosive Devices Development Laboratory. This building houses a world class explosive dynamics and spectroscopy laboratory, with capabilities for real-time monitoring of reacting energetic materials. Many of the spectroscopic techniques are specifically tailored for studying explosive phenomena and addressing basic questions of energetic material safety and performance. The facility can employ various initiation mechanisms, including conventional detonators, planar shock waves from projectile impact using a light-gas gun, high heating rate experiments using a pulsed dye laser and direct optical initiation.

-Building 935 - Neutron Generator Test Facility. This obsolete and inadequate facility is still required for testing developmental explosive and electronic neutron generators. These capabilities are scheduled to move to the new ECF.

-Building 940 - SCB Testing \& Explosive Ignition Lab. This facility allows specialized and controlled testing of semiconductor bridge (SCB) prototypes. It also houses a 400 Watt $\mathrm{Nd}$-YAG laser for low-energy, explosive ignition studies; a light electronic area for testing firing sets and other electronic assemblies; and photomicroscopy equipment for examination and post test analyses.

In our Tech Area III:

-Building 6510 - Water Impact Facility. This facility provides capabilities in the areas of water entry and ice penetration studies, cavitation, underwater explosives, and hydrostatic pressure.

-Buildings 6520 and 6526 - Centrifuge Facilities. These facilities are used in a variety of dynamic testing functions.

-Building 6530 - Radiant Heat Facility. This is a general purpose thermal test facility used for controlled temperature of heat flux testing. 
- Building 6630 - Climatic Test Facility. This facility can reproduce the thermal conditions associated with virtually any anticipated operating environment.

-Building 6730 - Force and Pressure Test Facilities. Although actually housed in a number of structures that use Building 6730 as an operational center, these capabilities are used to simulate both expected use conditions and, as well as conceivable, the abnormal environments that the product could encounter.

-Buildings 6741 and 6742 - Rocket Sled Track. This facility offers unique services in the areas of testing techniques and instrumentation capabilities.

-Building 6750 - Impact Test Facility. This facility, also known as the Gun Site Facility, provides important capabilities in the areas of armor evaluation, penetration thresholds and phenomena, impact and vulnerability studies, acceleration and flight dynamics, and rocket thrust/time curves.

In our Tech Area IV:

-Building 961 - MITE and DEMON Facilities. These two accelerators are being used for the development of the next generation of affordable advanced modular pulsed power simulators.

- Building 963 - High Power Microwave Test Facility. This facility is being constructed to allow the whole body irradiation of military hardware to characterize and reduce weapon vulnerability to a potential high power microwave threat. Building 963 also currently houses our coilgun Electromagnetic Launcher and the RHEPP and will soon house the Flight Dynamics Laboratory, a facility that provides critical support to efforts involving the STARS missile.

- Building 970 - Hermes III, SABRF, and Saturn. Hermes III is primarily operated for nuclear effects testing; however, it is also the primary test bed for the development of intense gamma ray simulators and the development of both the Externally Driven Nuclear Assembly (EDNA) and the Laboratory Microfusion Facility (LMF), both of which will reduce our reliance on underground testing. In the same building, SABRE is also developing technology that is an important step on the road to the LMF and Saturn is the world's most energetic pulsed $x$-ray source. By driving imploding plasmas for $x$ ray production, Saturn contributes substantially to our threat assessment mission in $x$-ray lasers and to radiation flow studies for both inertial fusion and weapons physics.

In our Tech Area V:

-Building 6588 - Annular Core Research Reactor (ACRR). The ACRR is a pool-type reactor that is capable of both pulsed and steady state operation and tailored transient rod withdrawal. In addition to its primary function in testing electronics, materials, and fissile 
components, the facility is al so used for research associated with reactor safety and FALCON.

-Building 6593 - Sandia Pulsed Reactor III (SPRIII). The SPRIII is a fast burst reactor with both pulsed and steady state capabilities. In addition to meeting high neutron fluence or pulsed high dose requirements for the testing of electronics, it is also important in research associated with FALCON.

In our Coyote Canyon Test Complex:

-Land Use Permit KAFB-R-OG-87-1 - Robotic Vehicle Range (RVR). The RVR is a two hundred acre open range for testing vehicles by remote control.

-Land Use Permit KAFB-R-0G-87-8 - Lurance Canyon Burn Site. These fire testing capabilities are used to simulate the effects of transportation and handling incidents in support of nuclear safety studies and to evaluate shipping containers.

-Land Use Permit DACA 47-4-72-42 - Aerial Cable Facilities. These facilities provide an affordable alternative to very wide range of testing requirements.

At our site near Livermore. California:

-Building 914 - Applied Mechanics Laboratories.

-Building 916 - Physics and Materials.

-Building 923 - Radiography Facility.

-Buildings 955 and 956 - Environmental Testing Labs.

-Building 966 - High Pressure Test Facility.

On the Tonopah Test Range:

- The Tonopah Test Range (TTR). The TTR is truly unique with regard to providing the opportunity for field scale testing of both systems and concepts with implications for the design of virtually all components, both nuclear and nonnuclear. Of particular current value are capabilities for testing in the areas of stealth and penetration technologies. The Davis Gun capabilities are of particular current importance to both the DOE and DOD because of the increasing possibility that the capability to attack deeply buried targets will be required.

At the Kauai Test Facility:

- The Kauai Test Facility (KTF). The existing assets and capabilities of the KTF, its remote and advantageous location, and its access to instrumentation support provided by the US Navy's Pacific Missile Range 
Facility make it a highly integrated and valuable facility for a wide range of testing operations. It is currently the only facility that is equipped to launch the STARS missile.

At the Nevada Test Site:

- Building CP1 - Area 6 Control Point. There are two Sandia facilities in this building. The Sandia Monitor Room houses the area radiation monitors, geophone and seismic monitoring equipment, and computer systems necessary for monitoring and control functions. These facilities are used by the DOE Test Controller during every event on the site and provide important support to Sandia, LANL, LLNL, and DNA activities during and after every event. The Sandia Arming and Firing Laboratory, in the same building, is used for the initial assembly, checking, and calibration of most of the arming and firing equipment, including the neutron generators, used at the NTS. These are unique capabilities at the NTS and are necessary to support the testing program.

- Building CP14 - Control Point Communications. This unique facility links the monitoring, control, and recording systems near the Area 12 Test Complex with the Area 6 Control Point.

-Building 12-909 - Area 12 Test Complex. This building houses data recording systems that support all underground nuclear weapons effects testing at the NTS. It supports all three of the DP Laboratories and the DNA.

At Pantex:

- Weapon Evaluation Test Laboratory. This facility, at Pantex, provides a wide range of important product performance data that can be of great value, particularly as we increase our already significant focus on designing for the entire life cycle of the product.

\section{B. Components}

There is a cyclical and iterative relationship between research, development, design, engineering, production, and stockpile maintenance. Thus, there are relatively fine 1 ines between Component Development and technology areas that are either upstream or downstream, including efforts focusing on Chemistry and Materials and System Engineering and Integration. With Sandia having responsibility for most of the distinct components used in nuclear weaponry, this program element is extensive at our sites.

With regard to electronics and photonics, specifically microelectronics and photonics, these are rapidly changing technologies that display explosive growth. They underlie the safety, use control, targeting, and AF\&F of nuclear weapons. Advances in these areas are critical to the surety mission, and four major facilities are important to our efforts. A fifth support facility is also noteworthy. 
-Building 858 - Microelectronics Development Laboratory. The silicon microelectronics projects that are currently underway in the Microelectronics Development Laboratory (MDL) will impact future DP programs in the areas of radiation hardened integrated circuits, ferroelectric nonvolatile memories, smart sensors, advanced packaging, and small micromechanical devices. The IC technology used for these projects is a modified version of Sandia's radiation hardened technology and the MDL serves as a alternate supplier of radiation hardened circuits for government applications. This facility will be adequate for government IC development for perhaps a decade, if the equipment set is continuously updated; however, the MDL can supply radiation tolerant circuits for only about three more years without significant equipment replacements.

-Building 893 - Compound Semiconductor Research Lab. Advanced device research and development in the areas of high speed electronics, microwave control circuits, laser arrays, IR detectors, and nonvolatile memories will have an important impact on DP programs and the compound Semiconductor Research Lab (CSRL) is vital in these areas. The clean room and equipment set for the CSRL will remain competitive for approximately three years, at which time significant equipment upgrades will be required. The clean room itself will become inadequate in about five years.

-Building 878 - Process Development Laboratory (PDL). This facility is truly critical to an extremely wide slice of our Component Development work, particularly as the interfaces between research and development, design, engineering, production, dismantlement, and waste disposition become more extensive and less distinct.

-Building 912 - Computer Center. This facility in Livermore also houses important microelectronics work.

-Building 806 - Research and Development Laboratory. Material for advanced compound semiconductor devices and circuits is grown in MBE and MOCVD reactors in this support facility in Albuquerque. The facility also houses semiconductor physics research and laser design and circuit testing functions for the CSRL.

With regard to explosive components, these activities will be more appropriately aodressed under Explosives. It should be noted, in any case, that many of the important facilities in this area are currently housed, in our Tech Area II, in some of oldest structures remaining in use at the Laboratories; structures which predate both Sandia Corporation and weapons assembly at Pantex. These structures are severely obsolete and grossly inadequate and, in this context, the most important facility in this technology area is the Explosives Components Facility $(E C F)$, a new facility that is only now being constructed.

Power sources are critical components. Many of our facilities are important to the maintenance of these technologies.

-Building 894 - Power Development Laboratory. This facility i- the hub of 
activities directly associated with the design and development of thermal batteries. Thermal batteries are the main power sources for most weapon systems, JTA's, and command disable systems. These batteries have unique characteristics which make them ideally suited to nuclear weapon applications and there are currently no appropriate replacements. Work on ambient temperature lithium batteries is also conducted in this facility. These operations are critical to the design and development of power supplies for all DP applications. As the use of lithium batteries in weapons systems continues to increase, our existing facilities will need to be upgraded and expanded.

-Building 919 - Explosive Devices Building. Specialized testing of power sources is currently conducted in this structure; however, the structure is obsolete and inadequate and this function will be relocated to the ECF.

Neutron generators are currently essential components. A number of our facilities are heavily involved with and important to these efforts.

- Building 805 - Research and Standards Laboratory. This facility provides necessary support in the areas of standards and calibration.

-Building 807 - Research and Development Laboratory. This building houses the High Voltage Pulse Facility, Transformer Development Laboratory, and Zetatron Test Facility.

-Buildings 840,841 , and 842 - Developmental Fabrication Shops. These older facilities provide a wide variety of necessary and, in some cases, unique services to our component development activities. They support our neutron generator efforts in the areas of coils and transformers, casting, machining, tooling, welding, and flame spray.

-Building 860 - Environmental Testing Laboratory. This is also an older facility that provides important environmental testing capabilities.

- Building 878 - Process Development Laboratory. This facility supports the neutron generator efforts in the areas of encapsulation, ceramics, mechanical processes and engineering, and component design support.

-Building 891 - Component Development Laboratory. This building houses a wide variety of capabilities, including, but not limited to, offices and computing facilities, spectrometry capabilities, ion source testing, permeation/desorption facilities, shelf life testing, switch tube laboratories, and a ferroelectric and ceramic rod laboratory. These capabilities and components are specialized, unique to nuclear weapon applications, and do not exist in the commercial sector.

-Building 935 - Neutron Generator Test Facility. This obsolete and inadequate facility is still required for testing developmental explosive and electronic neutron generators. These capabilities are scheduled to move to the new ECF. 
As should be expected, many of these facilities are important in more than one technology area. For example, Butlding 807, Research and Development Laboratory, and the Developmental Fabrication Shops in Building 840 also supply critical support to firing set technology development.

Bullding 894, our Power Development Laboratory, al so houses our Parachute Laboratory and Parachute Materials Quality Assurance Laboratory. High performance parachutes are critical components of DOE and DOD weapon systems, directly determining the performance, mission effectiveness, aircraft survivability/safety, and reliabllity of nuclear and advanced conventional munitions. Sandia is the only R\&D center in the US with the expertise required to design and develop these components. Thus, Sandia has the technical responsibility for design, production, and stockpile maintenance involving all War Reserve parachutes and, in this context, another of our facilities is of particular importance.

- Building 865 - Wind Tunnel Experimental Facility. This facility provides unique experimental capabilities, in the areas of aerodynamics and basic fluid mechanics, for weapon system design and a variety of other research and development applications. These applications include nuclear weapon stockpile evaluation, research in aerodynamics and fluid mechanics, guidance for building computational aerodynamics models, and validation of computational aerodynamics codes.

This is certainly not a complete listing of all of the capabilities needed to pursue our work in component development. For example, Buildings 805, 806, and 807 have already been mentioned as important facilities; however, they also house portions of our Metal Processing \& Fabrication Facility (MET), which is actually twenty nine different laboratory installations that support DP projects in the areas of welding, melting and casting, packaging techniques, solder joints, corrosion prevention, and the impact of ES\&H requirements on the materials and processes used in WR production. Although concentrated in Buildings 805,806 , and 807 ; the MET is actually distributed across a wide range of buildings in installations that are generally old, inefficient, and expensive to maintain.

This is also the case with regard to a number of capabilities that are more appropriately addressed in the program element for Chemistry and Materials. The need to enhance both the operational and ES\&H standards associated with all of these capabilities is a primary motivation behind the construction of two major new facilities, the Integrated Materials Research Laboratory (IMRL) and the Processing and Environmental Technologies Laboratory (PETL), both of which will be addressed in more detail under Chemistry and Materials.

There is also little doubt that the data acquired through the use of our Weapon Evaluation Test Laboratory at Pantex and our extensive systems testing capabilities, including our operations on the ionopah Test Range and at the Nevada Test Site, are critical to our Component Development efforts. Similarly, our development of the concept of full systems-level prototyping was also a major contribution in the area of components; however, these capabilities, including the new Weapons Production Primary 
Standards Laboratory, will be more appropriately addressed under system Engineering and Integration.

This is obviously not a complete and exhaustive list of our important facilities. Certainly, some of our most important facilities, including the Technology Support Center in our Tech Area $V$, have been omitted. Our power/telephone/communications systems are also essential to our operations and, in fact, the loss of Building 887, our Facilities Maintenance Building would literally cripple the site. It was perceived, however, that these capabilities do not fit your intent for this exercise. Although our response should serve as a good beginning for your purposes, it must still be kept in mind that our operations are highly interdependent and that the assumed purpose of your request was to gain a general understanding of our operations and not necessarily for us to provide a complete justification of our many assets. 

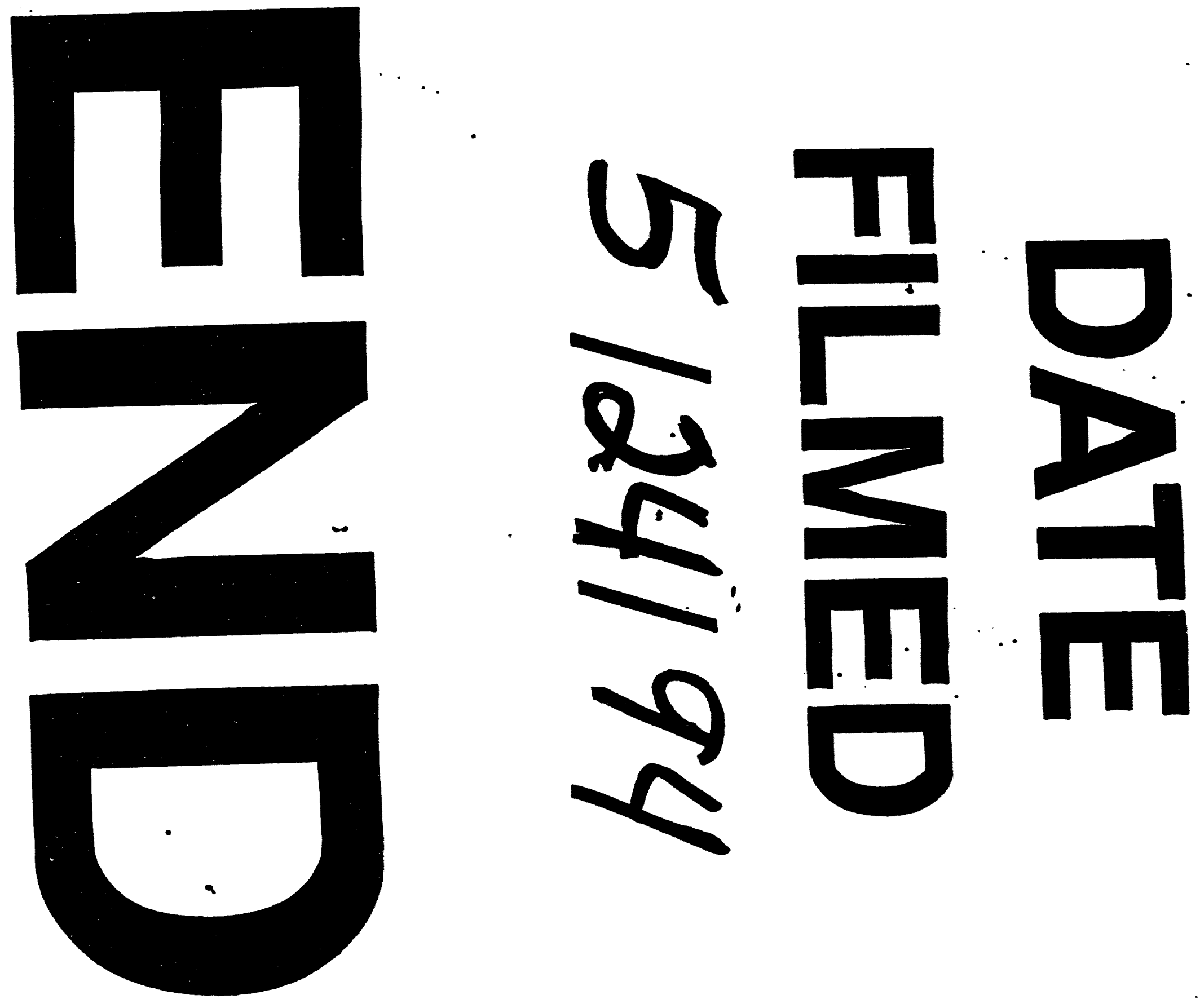
